\title{
EL MODELO DE ATENCIÓN PRIMARIA EN SALUD
}

\section{MODEL OF PRIMARY HEALTH CARE}

*Guillermo Restrepo Ch.

REC 2014; 20: 1-2

A nivel internacional y muy especialmente en América, hay un gran movimiento para dar un "Nuevo Enfoque" a los modelos de salud que actualmente se están desarrollando en los diferentes países, los cuales no han logrado satisfacer las expectativas que la población tiene en este aspecto, ya que los resultados medidos por indicadores especialmente diseñados para el efecto, no han alcanzado las metas que se esperaba obtener a pesar de los presupuestos cada vez mayores que se están dedicando a este sector.

En Colombia, desde la Ley 1438 del 2011, se trata de dar un enfoque a nuestra organización sanitaria en este sentido y el Ministerio de Salud está insistiendo en la necesidad de implementar cambios que lleven a lograr lo que allí se dispuso.

¿Cuál es pues el nuevo modelo que nos proponen?

Según la definición de Alma Atta, podemos resumir las bases de esta concepción en los siguientes puntos:

1. Atención a las personas en su grupo familiar y comunitario, acorde con el desarrollo social, incluida su participación.

2. Mediante la aplicación de una medicina científicamente actualizada, con una tecnología acorde con lo que la sociedad pueda costear

3. Como un proceso que contempla las diferentes complejidades que se requieran, para conducir el estado de salud en los diferentes momentos que esta suele presentar.

4. Contempla pues, la atención en todo el proceso de salud y enfermedad como son: Promoción, Prevención, Recuperación y Rehabilitación, su fragmentación es arbitraria y desconoce la marcha normal de la vida. Y finalmente,

5. Contempla la participación coordinada con otros sectores del desarrollo.

De este concepto tan amplio que merece ser analizado en toda su profundidad y para cada uno de los niveles responsables de su ejecución, solamente me quiero referir al último aspecto "Participación coordinada con otros sectores del desarrollo".

La mayoría de las interpretaciones que se hacen de este punto únicamente se refieren a su aplicación en lo relacionado con los prestadores de servicios y se hace énfasis en la necesidad que a nivel de la pequeña comunidad, que actúa como núcleo del sistema, el médico coordine su acción con los líderes políticos, religiosos, educadores, organizaciones comunitarias y otras instituciones de gobierno o sin ánimo de lucro, para conseguir cubrir todos los aspectos de salud en sus distintos niveles de prevención. Lograr esto es muy importante, ya que sin que se dé esta transversalidad, es imposible desarrollar un buen programa de atención primaria. 
Sin embargo no es solamente a ese nivel al que se refiere esta coordinación y si es necesario integración. Los niveles departamental y nacional deben lograr exactamente el mismo cometido.

Si algo merece ser destacado en las reformas que se hicieron a partir de la Constitución de 1991, como fueron la Ley 30 de 1992 para educación, la Ley 100 del 1993 para salud, la modificación de la estructura de la justicia, los cambios en agricultura, la flexibilización de la fuerza laboral y finalmente los tratados de libre comercio, fue su gran coherencia para montar un estado neoliberal.

De la misma manera, para hacer una transformación en el modelo de salud hacia la Atención Primaria, es necesario contar con una acción coordinada al más alto nivel, en donde haya una decisión política clara y coherente, indicando que se entiende lo que se va hacer, su trascendencia, y que además de la reforma necesaria que se haga en salud, es imperativo realizar cambios en los otros sectores, los cuales son fundamentales para que el modelo pueda operar eficientemente. Se debe entender claramente pues, cómo opera un Macro Sistema.

Solamente quiero mencionar aquí las implicaciones que esto tiene en el sector educativo y en el de trabajo y sobre todo en el manejo político que necesita el sistema, para poder desarrollar en forma eficiente el modelo.

Si queremos pues, acogernos a este modelo, hagámoslo bien, no provoquemos una frustración más y derroche de recursos y esfuerzos que no van a dar el fruto esperado. Los países latinoamericanos están enfrentando en este momento el Tercer gran saqueo de su historia en donde nuestro sector se incorporará claramente como mercancía de las grandes multinacionales. No hagamos abortar el desarrollo del modelo como lo ha hecho en buena parte el de Democracia Liberal en nuestros países, que solo ha conseguido una caricatura imperfecta de lo que se pretendía.

Guillermo Restrepo Ch. MD, MPH Editor Asistente REC 